DOI: https://doi.org/10.24144/2409-6857.2018.1(51).53-58

УДК 334.02

Сержанов В.В., Кубиний Н.Ю., Минкович В.Т.

\title{
ДОВЕРИЕ КАК УПРАВЛЕНЧЕСКИЙ МЕХАНИЗМ ПОДГОТОВКИ КОНКУРЕНТОСПОСОБНЫХ СПЕЦИАЛИСТОВ
}

\begin{abstract}
Статья посвящена результатам исследования состояния доверия студентов университета к преподавателям и между собой как рычага управления образовательным процессом. Определень уровень вертикального (к преподавателям) и горизонтального (между студентами) доверия, а также в системе координат отмечена точка, отражающая интегральное доверие. Предложень пути совершенствования управления образовательным прочессом в высшей школе на основе применения механизма доверия в университете.
\end{abstract}

Ключевье слова: доверие, управление, механизм, университет, качество знаний.

Постановка проблемы. Интеграция Украины в мировое сообщество закономерно приносит не только бонусы для страны, но и обуславливает появление системных вызовов, создающих обструкции формированию еe конкурентоспособности. Образование как стратегическая сфера развития общества, государства и экономики не избежало участия в конкурентной борьбе с сильными мировыми системами подготовки специалистов, успешно существующими многие сотни лет. Угрозы, возникающие как в кадровой сфере университетов, так и в студенческом секторе, связаны с контингентом учащихся, их количеством и качеством образования. В этой связи на первый план выходит задача трансформации системы образования в Украине, направленная на подготовку кадров, способных работать в экономике знаний, создавать и внедрять инновации, быть готовыми к постоянным и кардинальным изменениям бизнеса и его окружающего мира.

Стратегическая цель обеспечения конкурентоспособности украинского образования и, соответственно, его выпускников на мировых рынках труда предполагает

(c) Сержанов Виталий Викторович, к.э.н., доц., декан экономического факультета, ГВУЗ «Ужгородский национальный университет», г. Ужгород, тел..: 0501001070, e-mail: vitaliy.serzhanov@uzhnu.edu.ua

Кубиний Наталья Юрьевна, к.э.н., профессор кафедры экономики предприятия, ГВУЗ «Ужгородский национальный университет», г. Ужгород, тел.: 0506751412, e-mail: natalya.kubiniy@uzhnu.edu.ua

Минкович Виктория Тарасовна, старший преподаватель кафедры финансов и банковского дела ГВУЗ «Ужгородский национальный университет», г. Ужгород, тел.: 0506634053, e-mail: victoria.minkovych@uzhnu.edu.ua привлечение в организацию работы университетов новых механизмов, способствующих решению двух основных задач: a) повышению качества образования; б) росту эффективности функционирования образовательной системы в целом и университетов в частности.

В этой связи привлекает внимание доверие не только как институционально-культурная норма, но и как механизм управления эффективностью образовательного процесса. Доверие как фактор остается вне внимания современных управленцев в области образования, что позволяет рассматривать его внедрение как своего рода управленческую новацию, способствующую созданию конкурентных преимуществ учебного заведения, ориентирующегося на использование инновационных стратегий развития.

Обзор публикаций. Проблема доверия не является новой для современной научной мысли, но рассматривается главным образом в сфере политики, финансов и банковского дела, страхового бизнеса, маркетинга.

Сущность доверия как фактора экономической деятельности рассмотрена в трудах Лысенко В.В. [5], Мальцевой А.П. [6], Кривошеевой-Медянцевой Д.Д. [3] и других. Однако факторный подход не раскрывает роли и значения доверия в обеспечении цели функционирования организации.

Среди последних публикаций целесообразно отметить статью Кубиний В., Маргитич В., Пахтер Ю., (2016), в которой сделана попытка проанализировать уровень доверия на предприятиях Закарпатской области, при этом образовательные учреждения не были охвачены исследованием, что значительно снижает значимость представленных авторами результатов [4]. 
Большой интерес вызывают результаты исследования Aviv Kidron и Shay S. Tzafrir (2016), которые в своей статье иллюстрируют вывод о том, что «доверие обеспечивает связь

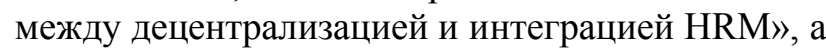
это является достаточно важным для формирования синергии при организации работы в команде [1]. При этом авторы не раскрывают достаточно полно механизмы формирования синергетических факторов на основе применения доверия в команде, что затрудняет его практическую имплементацию.

Доверие как механизм управления бизнесом, организацией, в том числе университетом, нашло ограниченное внимание.

Целью данной работы является обоснование путей повышения доверия в образовательном процессе высшей школы, что обеспечивает повышение качества знаний студентов и их конкурентоспособность.

Методология исследования избрана в соответствии с рекомендациями оценки доверия, предложенными Й. Алтманом и Н. Кубиний (2016): «При проведении полевых исследований были выделены вертикальный и горизонтальный виды доверия. Вертикальным определено доверие между работниками линейного уровня; соответственно, горизонтальным было названо доверие между коллегами. Уровень доверия был оценен по шкале от 0 до 5 баллов («5»максимальный уровень, «0» - отсутствие доверия или недоверия. Уровень недоверия также оценены по пятибалльной шкале, где «0»отсутствие недоверия (как и доверия), а «-5»показатель полного недоверия» [2]. В данном исследовании доверие вертикальное измеряется вектором студент-преподаватель, горизонтальное - это доверие между студентами. Для интегральной оценки уровня доверия определена точка в системе координат, которая отвечает вертикальному уровню, отраженному по вертикальной шкале, и соответственно, горизонтальному уровню доверия, отмеченному на горизонтальной оси. Квадрант, образованный положительными осями, характеризует зону синергии, в которой вертикальное и горизонтальное доверие действуют в одном направлении, усиливая эффект управления. Зона, образованная положительной осью вертикального доверия и отрицательной осью горизонтального, свидетельствует о том, что между студентами доверие практически отсутствует при наличии доверия к руководству. Данная зона названа Альтманом Й. и Кубиний Н.Ю. зоной социальной ямы. Зона, сформированная позитивным доверием к коллегам и негативным к менеджменту, - поле потенциального оппортунизма. Четвертый квадрант системы координат, сформированный отрицательными значениями вертикальной и горизонтальной осей, является характеристикой полного управленческого фиаско.

Обследованием охвачены студенты первого и четвертого курса экономического факультета Ужгородского национального университета в полном составе, что свидетельствует о достоверности результатов.

В процессе исследования кроме полевого анкетирования и геометрической интерпретации использованы методы монографический, научной абстракции, классификации и др.

Результаты исследования. Среди современных инструментов управления, как людьми, так и процессами незаслуженно забытым является доверие, которое способствует повышению экономических, социальных и психологических индикаторов управления образованием. Для понимания роли доверия и возможности его использования как инструмента управления целесообразно диагностировать состояние доверия в университете. Это позволит не только определить социальный потенциал дальнейшего развития, но и выявить обструкции совершенствования учебного процесса. Все это обусловило необходимость проведения исследования уровня доверия на экономическом факультете Ужгородского национального университета. Обследованием охвачены студенты первого и последнего курсов бакалаврата с детализацией по специальностям и полу. Результаты исследования показали, что уровень вертикального доверия (студентов к преподавателям) в целом достаточно высокий: и на первом курсе, и на четвертом - 3,05 (см. табл.1).

Уровень горизонтального доверия на четвертом курсе ниже, чем на первом. Если на первом курсе студенты оценили доверие между собой на 3,16 пункта из 5 возможных, то выпускники определили 3,11 пункта.

Результаты анкетирования позволяют сделать вывод: доверие находится на достаточно высоком уровне, но механизм доверия не используется в достаточной мере в управлении учебным процессом. Заслуживает внимания тот факт, что уровень доверия у девушек на первом курсе к преподавателям значительно выше среднего - 3,13, в то время как юноши оценили доверие лишь на уровне 2,92 . Обратная ситуация сложилась на четвертом курсе. 
Таблица 1

Средний уровень вертикального и горизонтального доверия студентов первого и четвертого курсов экономического факультета Ужгородского национального университета *

\begin{tabular}{|l|l|l|l|}
\hline \multicolumn{2}{|l|}{ Средний уровень вертикального доверия } & \multicolumn{3}{|l|}{ Средний уровень горизонтального доверия } \\
\hline 1 курс & 3,05 & \multicolumn{1}{|l|}{1 курс } & 3,16 \\
\hline В том числе: & 3,13 & В том числе: & \\
\hline Девушки & 2,92 & Девушки & 3,00 \\
\hline Юноши & 3,05 & Юноши & 3,46 \\
\hline 4 курс & 4 курс & 3,11 \\
\hline В том числе: & В том числе: \\
\hline Девушки & 2,59 & Девушки & 2,77 \\
\hline Юноши & 3,57 & Юноши & 3,49 \\
\hline
\end{tabular}

* (составлена авторами на основе результатов опроса)

Студенты-девушки в среднем оценили доверие к преподавателям на 2,59 пункта, в то время как юноши - на 3,57. Снижение доверия к четвертому курсу можно объяснить усилением конкуренции между студентами за результаты оценивания знаний, которые могут повлиять на их будущее трудоустройство. Что касается горизонтального доверия, то есть доверия между студентами, его средний уровень выше, чем уровень доверия к преподавателям. На первом курсе данный показатель составил 3,16 пункта, на четвертом - 3,11. Уровень доверия между юношами значительно выше, чем уровень доверия между девушками.

Для интегральной оценки уровня доверия использован геометрический метод системы координат, который позволяет на плоскости определить точку соприкосновения вертикального и горизонтального доверия, что отражено на рис.1.

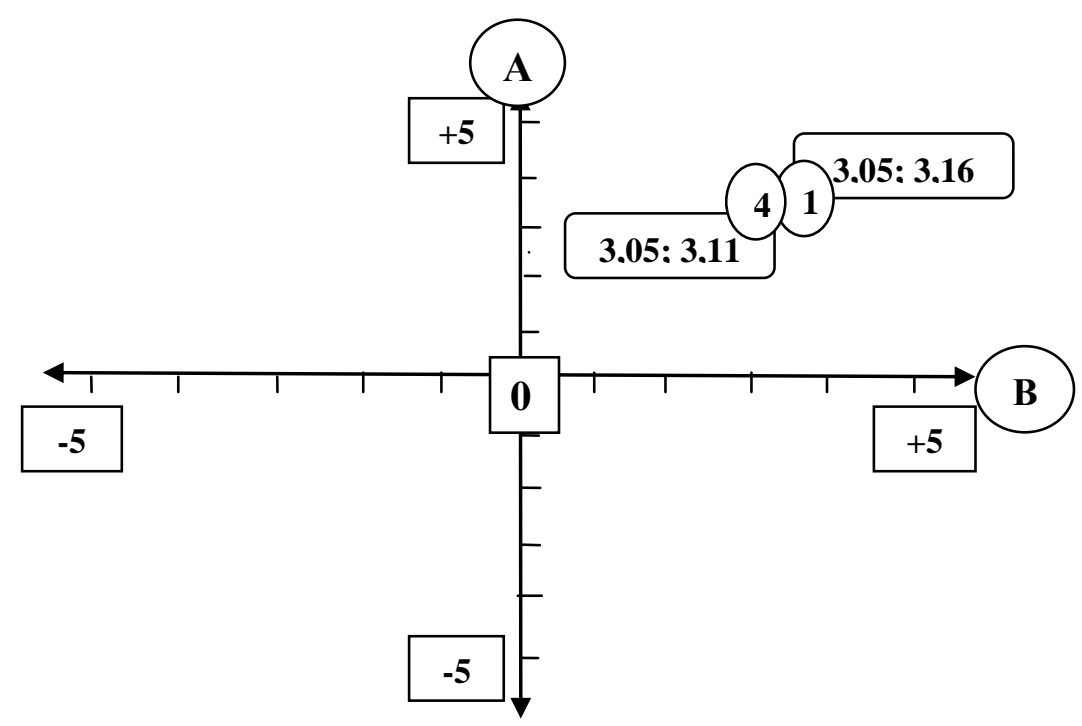

Рис. 1. Координаты доверия студентов экономического факультета Ужгородского национального университет*

\section{*Составлено авторами}

Размещение интегрированных точек доверия студентов первого курса с координатами 3,$05 ; 3,16$ и студентов 4 курса с координатами 3,05;3,11 (рис. 1) показывает, что и вертикальное, и горизонтальное доверие всех студентов находится в секторе, который характеризуется положительным значением обоих видов доверия.

Это, в свою очередь, позволяет сделать вывод о том, что доверие действует как синергетическая система, обеспечивающая дополнительный эффект от позитивной однонаправленности обоих видов доверия, что указывает на высокий социальный потенциал развития экономического факультета.

Определенный интерес представляет дифференциация уровня доверия по специальностям, что представлено в таблице 2 и 3. 
Таблица 2

Уровень доверия студентов 1 курса в разрезе спеціальностей*

\begin{tabular}{|c|c|c|c|c|c|c|}
\hline & \multicolumn{2}{|c|}{$\begin{array}{c}\text { «Экономика } \\
\text { предприятия» }\end{array}$} & \multicolumn{2}{|c|}{$\begin{array}{c}\text { «Финансы, банковское } \\
\text { дело и страхование» }\end{array}$} & \multicolumn{2}{|c|}{$\begin{array}{c}\text { «Учет, аудит и } \\
\text { налогообложение» }\end{array}$} \\
\hline & $\begin{array}{l}\text { Девушки } \\
\text { Кол. / \% }\end{array}$ & $\begin{array}{l}\text { Юноши } \\
\text { Кол. / \% }\end{array}$ & $\begin{array}{l}\text { Девушки } \\
\text { Кол. / \% }\end{array}$ & $\begin{array}{l}\text { Юноши } \\
\text { Кол. / \% }\end{array}$ & $\begin{array}{l}\text { Девушки } \\
\text { Кол. / \% }\end{array}$ & $\begin{array}{l}\text { Юноши } \\
\text { Кол. / \% }\end{array}$ \\
\hline \multicolumn{7}{|c|}{ Оченка уровня вертикального доверия } \\
\hline$《+5 »$ & 0 & 0 & $3 / 21,4 \%$ & $1 / 16,7 \%$ & 0 & 0 \\
\hline$«+4 »$ & 0 & $1 / 25 \%$ & $5 / 35,7 \%$ & $2 / 33,3 \%$ & $3 / 37,5 \%$ & $1 / 33,3 \%$ \\
\hline$《+3 »$ & $2 / 100 \%$ & $2 / 50 \%$ & $4 / 28,6 \%$ & $2 / 33,3 \%$ & $4 / 50 \%$ & $1 / 33,3 \%$ \\
\hline$《+2 »$ & 0 & 0 & $1 / 7,15 \%$ & 0 & 0 & $1 / 33,3 \%$ \\
\hline$《+1 »$ & 0 & 0 & $1 / 7,15 \%$ & 0 & 0 & 0 \\
\hline$《 0 »$ & 0 & $1 / 25 \%$ & 0 & $1 / 16,7 \%$ & 0 & 0 \\
\hline$\langle-5 »$ & 0 & 0 & 0 & 0 & $1 / 12,5 \%$ & 0 \\
\hline Не определился & 0 & 0 & 0 & 0 & 0 & 0 \\
\hline Средний уровень доверия & \multicolumn{2}{|c|}{2,7} & \multicolumn{2}{|c|}{3,5} & \multicolumn{2}{|c|}{2,5} \\
\hline \multicolumn{7}{|c|}{ Оиенка уровня горизонтального доверия } \\
\hline$《+5 »$ & 0 & 0 & $2 / 14,3 \%$ & $2 / 33,3 \%$ & 0 & 0 \\
\hline$《+4 »$ & 0 & $2 / 50 \%$ & $3 / 21,4 \%$ & $3 / 50 \%$ & $2 / 25 \%$ & $1 / 33,3 \%$ \\
\hline$\ll+3 »$ & $2 / 100 \%$ & $1 / 25 \%$ & $5 / 35,7 \%$ & $1 / 16,7 \%$ & $6 / 75 \%$ & $1 / 33,3 \%$ \\
\hline$\ll+2 »$ & 0 & 0 & 0 & 0 & 0 & $1 / 33,3 \%$ \\
\hline$《+1 »$ & 0 & 0 & $3 / 21,4 \%$ & 0 & 0 & 0 \\
\hline$\ll 0 »$ & 0 & $1 / 25 \%$ & $1 / 7,2 \%$ & 0 & 0 & 0 \\
\hline Не определился & 0 & 0 & 0 & 0 & 0 & 0 \\
\hline Средний уровень доверия & \multicolumn{2}{|c|}{2,8} & \multicolumn{2}{|c|}{3,3} & \multicolumn{2}{|c|}{3,2} \\
\hline
\end{tabular}

* Составлена авторами на основе результатов опроса

На первом курсе наиболее широкий разброс мнений представлено результатами анкетирования девушек специальности «финансы». Такой разброс показывает, что не сложился коллектив, отношения не нашли определенной стабильности.

В таблице 3 представлены результаты оценки доверия студентами четвертого курса.

Таблица 3

Уровень доверия студентов 4 курса в разрезе спеціальностей*

\begin{tabular}{|c|c|c|c|c|c|c|}
\hline & \multicolumn{2}{|c|}{$\begin{array}{c}\text { «Экономика } \\
\text { предприятия» }\end{array}$} & \multicolumn{2}{|c|}{ «Финансы и кредит» } & \multicolumn{2}{|c|}{ «Учет и аудит» } \\
\hline & $\begin{array}{c}\text { Девушки } \\
\text { Кол. / \% } \\
\end{array}$ & $\begin{array}{l}\text { Юноши } \\
\text { Кол. /\% } \\
\end{array}$ & $\begin{array}{c}\text { Девушки } \\
\text { Кол. / \% }\end{array}$ & $\begin{array}{l}\text { Юноши } \\
\text { Кол. /\% } \\
\end{array}$ & $\begin{array}{l}\text { Девушки } \\
\text { Кол. / \% }\end{array}$ & $\begin{array}{l}\text { Юноши } \\
\text { Кол. /\% } \\
\end{array}$ \\
\hline \multicolumn{7}{|c|}{ Оченка уровня вертикального доверия } \\
\hline$《+5 »$ & $3 / 37,5 \%$ & $5 / 55,6 \%$ & 0 & $5 / 31,25 \%$ & $2 / 9,5 \%$ & $2 / 20 \%$ \\
\hline$\ll+4 »$ & $3 / 37,5 \%$ & $4 / 44,4 \%$ & $7 / 70 \%$ & $2 / 12,5 \%$ & $2 / 9,5 \%$ & $1 / 10 \%$ \\
\hline$《+3 »$ & $2 / 25 \%$ & 0 & $2 / 20 \%$ & $7 / 43,75 \%$ & $6 / 28,6 \%$ & $4 / 40 \%$ \\
\hline$《+2 »$ & 0 & 0 & 0 & $1 / 6,25 \%$ & $1 / 4,8 \%$ & $1 / 10 \%$ \\
\hline$《+1 »$ & 0 & 0 & 0 & 0 & $1 / 4,8 \%$ & 0 \\
\hline$《 0 »$ & 0 & 0 & $1 / 10 \%$ & 0 & $4 / 19 \%$ & $1 / 10 \%$ \\
\hline$\langle-5 »$ & 0 & 0 & 0 & 0 & $1 / 4,8 \%$ & 0 \\
\hline Не определился & 0 & 0 & 0 & $1 / 6,25 \%$ & $4 / 19 \%$ & $1 / 10 \%$ \\
\hline Средний уровень доверия & \multicolumn{2}{|c|}{4,5} & \multicolumn{2}{|c|}{3,5} & \multicolumn{2}{|c|}{2,0} \\
\hline \multicolumn{7}{|c|}{ Оиенка уровня горизонтального доверия } \\
\hline$《+5 »$ & $3 / 37,5 \%$ & $6 / 66,7 \%$ & 0 & $3 / 18,75 \%$ & $2 / 9,5 \%$ & $3 / 30 \%$ \\
\hline$\ll+4 »$ & $3 / 37,5 \%$ & $3 / 33,3 \%$ & $6 / 60 \%$ & $6 / 37,5 \%$ & $5 / 23,8 \%$ & 0 \\
\hline$《+3 »$ & $2 / 25 \%$ & 0 & $2 / 20 \%$ & $4 / 25 \%$ & $5 / 23,8 \%$ & $3 / 30 \%$ \\
\hline$《+2 »$ & 0 & 0 & $1 / 10 \%$ & $1 / 6,25 \%$ & 0 & $1 / 10 \%$ \\
\hline$\ll+1 »$ & 0 & 0 & $1 / 10 \%$ & 0 & 0 & $1 / 10 \%$ \\
\hline$《 0 »$ & 0 & 0 & 0 & 0 & $4 / 19 \%$ & $1 / 10 \%$ \\
\hline$\langle-3 »$ & 0 & 0 & 0 & 0 & $1 / 4,8 \%$ & 0 \\
\hline Не определился & 0 & 0 & 0 & $2 / 12,5 \%$ & $4 / 19 \%$ & $1 / 10 \%$ \\
\hline Средний уровень доверия & \multicolumn{2}{|c|}{4,4} & \multicolumn{2}{|c|}{3,3} & \multicolumn{2}{|c|}{2,2} \\
\hline
\end{tabular}

* Составлена авторами на основе результатов опроса 
Важным направлением совершенствования системы управления качеством знаний в университете является наличие цели и видения развития факультета, принимаемых всеми студентами и преподавателями.

Кроме того, в условиях повышения полинациональности состава студентов и препо- давателей, доверие может быть использовано как фактор культурного развития, формирования атмосферы толерантности и уважения к разным национальностям, использования многокультурности как своеобразного «бульона» возникновения новых управленческих, научных и образовательных идей.

Таблица 4

Результаты анкетирования студентов первого курса экономического факультета Ужгородского национального университета*

\begin{tabular}{|c|c|c|c|c|c|c|}
\hline & \multicolumn{2}{|c|}{$\begin{array}{c}\text { «Экономика } \\
\text { предприятия» }\end{array}$} & \multicolumn{2}{|c|}{$\begin{array}{c}\text { «Финансы, банковское } \\
\text { дело и страхование» }\end{array}$} & \multicolumn{2}{|c|}{$\begin{array}{c}\text { «Учет, аудит и } \\
\text { налогообложение» }\end{array}$} \\
\hline & $\begin{array}{l}\text { Девушки } \\
\text { Кол. / \% }\end{array}$ & $\begin{array}{l}\text { Юноши } \\
\text { Кол. /\% }\end{array}$ & $\begin{array}{l}\text { Девушки } \\
\text { Кол. / \% }\end{array}$ & $\begin{array}{l}\text { Юноши } \\
\text { Кол. } / \%\end{array}$ & $\begin{array}{l}\text { Девушки } \\
\text { Кол. / \% }\end{array}$ & $\begin{array}{l}\text { Юноши } \\
\text { Кол. } / \%\end{array}$ \\
\hline $\begin{array}{l}\text { Считаете ли Bbl, что } \\
(\text { и вообще между людьми)? }\end{array}$ & вера $\quad$ в & общую & \multicolumn{2}{|c|}{ способствует } & 6 & оллективе \\
\hline Да & $1 / 50 \%$ & $3 / 75 \%$ & $10 / 71,4 \%$ & $6 / 100 \%$ & $5 / 62,5 \%$ & $1 / 33,3 \%$ \\
\hline Нет & 0 & 0 & $1 / 7,2 \%$ & 0 & 0 & $1 / 33,3 \%$ \\
\hline Сложно ответить & $1 / 50 \%$ & $1 / 25 \%$ & $3 / 21,4 \%$ & 0 & $3 / 37,5 \%$ & $1 / 33,3 \%$ \\
\hline \multicolumn{7}{|c|}{ Как Вы считаете, уровень доверия выше между студентами: } \\
\hline Одной национальности & $1 / 50 \%$ & 0 & $4 / 28,6 \%$ & $2 / 33,3 \%$ & $2 / 25 \%$ & 0 \\
\hline Разных национальностей & 0 & 0 & 0 & 0 & 0 & $1 / 33,3 \%$ \\
\hline $\begin{array}{l}\text { Национальность на уровень } \\
\text { доверия не влияет }\end{array}$ & $1 / 50 \%$ & $4 / 100 \%$ & $10 / 71,4 \%$ & $4 / 66,7 \%$ & $6 / 75 \%$ & $2 / 66,7 \%$ \\
\hline
\end{tabular}

* Составлена авторами на основе результатов опроса

Результаты анкетирования, представленные в таблицах 4 и 5, способствуют выявлению позиции студентов относительно роли совместных ценностей и национальной принадлежности на уровень доверия в университете. Данные таблицы 4 свидетельствуют о том, что на первом курсе понимание стратегического управления, наличие миссии, видения развития образования еще не сформировано полностью.

Таблица 5

Результаты анкетирования выпускников четвертого курса (бакалавров) экономического факультета Ужгородского национального университета*

\begin{tabular}{|c|c|c|c|c|c|c|}
\hline & \multicolumn{2}{|c|}{$\begin{array}{c}\text { «Экономика } \\
\text { предприятия» }\end{array}$} & \multicolumn{2}{|c|}{ «Финансы и кредит» } & \multicolumn{2}{|c|}{ «Учет и аудит» } \\
\hline & $\begin{array}{l}\text { Девушки } \\
\text { Кол. / \% }\end{array}$ & $\begin{array}{l}\text { Юноши } \\
\text { Кол. /\% }\end{array}$ & $\begin{array}{l}\text { Девушки } \\
\text { Кол. /\% }\end{array}$ & $\begin{array}{l}\text { Юноши } \\
\text { Кол. } / \%\end{array}$ & $\begin{array}{l}\text { Девушки } \\
\text { Кол. / \% }\end{array}$ & $\begin{array}{l}\text { Юноши } \\
\text { Кол. } / \%\end{array}$ \\
\hline $\begin{array}{l}\text { Считаете ли Bы, что } \\
\text { (и вообще между людьми)? }\end{array}$ & вера & общую & cnoc & cmвует & ерию & оллективе \\
\hline Да & $7 / 87,5 \%$ & $7 / 77,8 \%$ & $9 / 90 \%$ & $15 / 93,75 \%$ & $11 / 52,4 \%$ & $8 / 80 \%$ \\
\hline Нет & 0 & $1 / 11,1 \%$ & $1 / 10 \%$ & 0 & $5 / 23,8 \%$ & $1 / 10 \%$ \\
\hline Сложно ответить & $1 / 12,5 \%$ & $1 / 11,1 \%$ & 0 & $1 / 6,25 \%$ & $5 / 23,8 \%$ & $1 / 10 \%$ \\
\hline \multicolumn{7}{|c|}{ Как Вы считаете, уровень доверия выше между студентами: } \\
\hline Одной национальности & $3 / 37,5 \%$ & $4 / 44,4 \%$ & $3 / 30 \%$ & $9 / 56,25 \%$ & $2 / 9,5 \%$ & $7 / 70 \%$ \\
\hline Разных национальностей & 0 & 0 & $1 / 10 \%$ & $1 / 6,25 \%$ & 0 & 0 \\
\hline $\begin{array}{l}\text { Национальность на уровень } \\
\text { доверия не влияет }\end{array}$ & $5 / 62,5 \%$ & $5 / 55,6 \%$ & $6 / 60 \%$ & $6 / 37,5 \%$ & $19 / 90,5 \%$ & $3 / 30 \%$ \\
\hline
\end{tabular}

* Составлена авторами на основе результатов опроса

Как следует из данных, представленных в таблице 5, абсолютное большинство студентов четвертого курса поддерживают мысль о наличии связи между общими ценностями, к которым принадлежит идеология развития, и уровнем доверия.
Результаты опроса о влиянии национальности на уровень доверия, представленные в таблицах 4 и 5, позволяют сделать вывод о том, что современные студенты готовы учиться и работать в полинациональном и многокультурном окружении, что позволяет им 
получить дополнительные возможности формирования будущей профессиональной конкурентоспособности.

Выводы. Результаты проведенного исследования показали, что на экономическом факультете Ужгородского национального университета доверие студентов к преподавателям и доверие между студентами находится на достаточно высоком уровне, что позволяет использовать данный инструмент как механизм синергии в стратегическом и оперативном управлении учебным процессом.

При этом целесообразным считаем выделить следующие направления повышения уровня доверия студентов, что служит фактором роста качества образовательных услуг экономического факультета Ужгородского национального университета:
1. Разработка культурной стратегии развития факультета с этическим кодексом взаимоотношений между преподавателями и студентами и этическими правилами в студенческой среде.

2. Для обеспечения открытости и объективности оценивания знаний студентов привлечение студенческого актива к процессу аттестации.

3. Совместное проведение социальнокультурных мероприятий, научных конференций, спортивных мероприятий, способствующих установлению чувства взаимной поддержки, уважения и доверия.

В дальнейшем запланировано исследовать поведение уровня доверия и его влияние на качество знаний, используя методы корреляционного анализа.

\section{СПИСОК ИСПОЛЬЗОВАННЫХ ИСТОЧНИКОВ}

1. Aviv Kidron, Shay S. Tzafrir, Ilan Meshoulam, (2016), "Allweneedistrust: trust and human resource management", Team Performance Management. - Vol. 22. -Iss 3/4 - pp. 139 - 155.

2. Алтман Й. Виды доверия и их оценка [Текст] / Й. Алтман, Н. Ю. Кубиний // Науковий вісник Ужгородського університету. Серія: Економіка; збірник наукових праць / редкол.: В.П. Мікловда, В.І. Ярема та ін. - Ужгород : Вид-во УжНУ "Говерла". - 2016. - Вип. 2 (48). - С. 148-152.

3. Кривошеева-Медянцева Д. Доверие как фактор экономического развития: исследование с позиции институциональной теории. - TERRA ECONOMICUS - 2013. - Том 11. - №2. - C. 15-20.

4. Кубіній В.В. Довіра як фактор конкурентоспроможності закарпатських підприємств / В. В. Кубіній, Ю. О. Пахтер, В. В. Маргітич // Міжнародний науковий журнал.- 2016. - № 8. -С. 111-115.

5. Лисенко В.В. Довіра як фактор розвитку підприємницької діяльності в агробізнесі / В. В. Лисенко // Глобальні та національні проблеми економіки : електронне наукове видання. - Вип. № 6. - 2015. - С. 194 - 199 [Електронний ресурс]. - Режим доступу: http://globalnational.in.ua/issue-6-2015/14-vipusk-6-lipen-2015-r/1012lisenko-v-vdovira-yak-faktor-rozvitku-pidpriemnitskoji-diyalnosti-v-agrobiznesi.

6. Мальцева А.П. Полноценное доверие: понятие, проблема, методика формирования / А.П.Мальцева // Власть. - Вип. № 7. - 2014. - С. 115 - 119.

\section{REFERENCES}

1. Aviv Kidron, \& Shay S. Tzafrir, \& Ilan Meshoulam, (2016). All we need is trust: trust and human resource management. Team Performance Management, Vol. 22, Iss 3/4, 139-155 [in English].

2. Altman, Y., \& Kubiniy, N. (2016). Vidyi doveriya i ih otsenka [The types of trust and their evaluation]. Naukoviy visnik Uzhgorodskogo universitetu. Seriya: Ekonomika. - Scientific Bulletin of Uzhhorod University. Series "Economics", 148-152 [in Russian]

3. Krivosheeva-Medjantseva, D. (2013). Doverie kak faktor ekonomicheskogo razvitiya: issledovanie s pozitsii institutsionalnoy teorii [Trust as a factor of economic development: studies conducted within the frame of institutional economic theory]. TERRA ECONOMICUS, 15-20 [in Russian].

4. Kubiniy, V., \& Pahter, Y., \& Marhytych, V. (2016). Dovira yak faktor konkurentospromozhnosti zakarpatskykh pidpryiemstv. [Trust as a factor of competitiveness of Transkarpatian enterprises]. Mizhnarodnyi naukovyi zhurnal International Scientific Journal, 111-115 [in Ukranian].

5. Lycenko, V. (2015). Dovira yak faktor rozvytku pidpryiemnytskoi diialnosti v ahrobiznesi [Trust as a factor in the development of entrepreneurial activity in agribusiness]. Hlobalni ta natsionalni problemy ekonomiky - Global and national problems of the economy, 194-199 [in Ukranian].

6. Mal'ceva, A. (2014). Polnotsennoe doverye: poniatye, problema, metodyka formyrovanyia [Full trust: concept, problem, methodology of formation]. Power - Vlast', 115-119 [in Russian

Одержано 15.03. 2018 p. 